\title{
Benefit Analysis on Rural Human Resource Development
}

\author{
Jiayong Liu \\ School of Economics and Business Administration, Yan'an University, Yan'an, 716000,China
}

Keywords: Rural human resource, Development benefit, Current problems, Effective measures

\begin{abstract}
The level of rural human resource development increasingly becomes an important factor which promotes social and economic development, which is not only related to obvious difference in urban and rural development and coordinating regional economic comprehensive benefit, but also an important reflection of the sustainable development strategy of economic society and the concept of building a harmonious society in human resource development and utilization field. Meanwhile, as a long-term development strategy, the concept of circular economy enjoys popular support, and the research on development benefit of rural human resource which adapts to this strategy also attracts wide attention. On the basis of human resource development and management experience, this paper discusses the current problems of rural human resource development and effective measures from perspective of concept and management, basic education, and social security for the purpose of providing some reference for relevant practice.
\end{abstract}

\section{Introduction}

The level of human resource development and utilization not only can reflect the integration and distribution of labor resources within specific period in one region, but also can be used as the basis of formulating economic development strategy. China has rich rural labor force; under the social background of advocating to develop circular economy, in order to obtain long-term economic benefit, it is required to get rid of the stale and take in the fresh as for development and management of rural human resource, combine with specific situation of rural human resource utilization, change traditional human resource development mode, break the shackle of concept and thought field, and utilize three-dimensional way of thinking to carry out comprehensive investigation and analysis on rural human resource development. The urgent affair is to enhance social value and practical ability of labor resource.

\section{Current situation and problems of rural human resource development}

China has a low development benefit of rural human resource, and this is a result obtained mainly from perspective of quality of human resource through comparison with development benefit of urban human resource. Take rural area of Zunyi City, Guizhou Province as an example: according to the random sampling survey in 2013, it shows that the proportion of illiteracy is $10.8 \%$, the proportion of people with degree of primary school education is $53.2 \%$, the proportion of people with degree of middle school education is $21.9 \%$, the proportion of people with high school education is only $9.0 \%$, and the proportion of people with technical secondary school education and above is $5.1 \%$. From macroscopic perspective, less than $30 \%$ of rural labor has accepted short-term training, and such training is accepted while they go out to work. However, people who have accepted the training of primary and intermediate vocational education only account for $3.51 \%$ and $0.12 \%$ respectively. The level of both basic cultural quality and skill quality of human resource is low, which is the key restricting the development benefit of rural human resource and also the problem that shall be urgently solved.

At current stage, there exist many management-related omissions in rural human resource development, and the resistance also exists in the implementation process of system and strategy. Furthermore, due to the fact that large quantity of rural population surges into cities, the problems such as idleness of rural land, low-efficient utilization of land resource, forest resource, and water 
resource happen, which causes certain influence on rural production and hinders local economic development to certain degree; therefore, it is unable to improve the quality of rural labor and a vicious circle mode is formed.

\section{Reasons which influence development benefit of rural human resource}

The human resource development process is a long-term and systematic engineering, and it is affected by multiple factors such as fund. In the rural human resource development process, there are following three reasons which influence the benefit:

\section{Concept and management factor}

The development benefit of modern economic society is closely related to integration and optimization of resource structure; meanwhile, the development is realized with the help of advanced management way; however, it is undoubted that the small-farmer awareness and passive thinking in traditional agricultural society still exist today, which hinders the labor force to exert their individual potential. On a long view, the benefit is considerable after reasonable investment and management on rural human resource, including economic benefit, skill benefit, improvement of personal quality, and potential benefit. The farmers' lagging and narrow concept hinders the development of rural economy to certain degree. The professional skills can't be trained, thus the rural labor is not capable of social post. For example, in Anhui Province, only 30\% of rural workers hold primary vocational skill qualification, but more than $80 \%$ of posts require primary vocational skill qualification, and $13 \%$ of posts require intermediate vocational skill qualification at minimum level. The lagging concepts cause the situation that the way of employment for rural labor is very single, the technology they master is very few, many post skills are not trained, and they frequently change their work in many fields and have low stability. Meanwhile, the social relevant institutions lack of necessary management for rural human resource, and the labor market construction lacks of perfect system and supervision mechanism; therefore, on one hand, the rural surplus labor without effective management has no long-term living guarantee; on the other hand, their skills can't be trained and practiced, and their ability can't be exerted, which intangibly consumes their valuable time and life.

\section{Rural basic education factor}

The degree of education of rural labor is generally low, which is closely related to rural investment of education cost. The educated time for rural and urban young people is 7.5 years and 10.5 years on average respectively; due to difference in time and fund investment, the degree of education of rural labor resource is generally level of primary school, which causes realistic bottleneck for exerting the potential of human resource. The 21st century is the era of knowledge-driven economy, and mastering and applying advanced scientific knowledge and skills plays a decisive role in promoting social and economic development and promoting the realization of self-value. However, most rural economic level can only maintain daily life, and no surplus fund can be invested in education. Therefore, China also adjusts the appropriation of educational expenditure; however, compared to the per capita in-budget shared expenditure level of urban primary and secondary school students, the per capital in-budget shared expenditure level for rural primary and secondary school is still very low, and the investment cost for training of labor skills of rural human resource is much less, which is related to serious insufficient investment of vocational education; the extremely insufficient training expenditure results in low quality and low skill level of rural labor force. Most of rural family income is used to pay their children's educational expense, and only very little part is used to invest their labor skills.

\section{Social security factor}

The rural social security level is relative low. For examples, compared to cities, the investment in rural medical and health service in China is also insufficient. China has numerous rural population, but the medical resource is very limited. On a national scale, $65 \%$ of rural population only enjoy $20 \%$ of medical resource. According to the statistical data in the end of 2010, the per capita expenditure of health care for Chinese urban and rural residents is RMB 1,635.4 yuan and RMB 513.6 yuan respectively; in terms of medical equipments, number of beds, number of medical workers, and 
number of registered nurses, the urban level is 2-3 times higher than rural level; in terms of medical workers' employment quality and service level, the rural level is far worse than urban level; besides, in rural area, only $31 \%$ of physicians have occupational qualification, and less than $30 \%$ of medical workers have professional title.

\section{Effective measures for improving the development benefit of rural human resource}

The efficient development of human resource is not only related to construction of people's livelihood, but also the basis for good and quick development of social economy; therefore, we shall keep up with the times, and adopt new way of thinking and development concept to fully dig out the potential of rural human resource and lay a good foundation for building harmonious and efficient economic construction. The development of rural human resource shall be consistent with structural features and basic demand of human resource so that it is able to adopt effective solution for specific problem and realize suiting the remedy to the case. As for currently existing problems, the following strategies can be adopted.

Firstly, in the development process, it is required to continuously emancipate our mind, change lagging concept and old management way, and make rural construction harmonious with core idea of social economy. In current social and economic development, the circular economy is regarded as core concept, thus the attention shall be paid to sustainability and flexibility in the development and management of human resource. The circular economy is the specific reflection of advocating sustainable economic development strategy; under the condition of increasingly short resource, through advocating recycling use of resource, improving re-input of waste materials into other production fields, and making the best use of everything, it is not only able to mitigate the use gap of resource, but also able to reduce resource consumption, save more financial resource, material resource and human resource, and bring benefit to contemporary people and later generations. Different from treatment after pollution, the circular economy pays attention to energy saving and consumption reduction in whole process of economic development, which enhances the harmony between economic development and surrounding and can create more comfortable and convenient living and production environment for people. Based on this environment of economic construction, the first step of rural human resource development is to arm the brain with brand-new production concept to promote them to abandon the thinking way of small-farmer awareness, review themselves and society from overall perspective, and continuously develop their potential to realize making the best use of everything and giving full scope to the talents. The management way shall be also flexible and it is adopted based on specific situation of each region and village. For example, the most crucial task for current rural human resource is to promote the transfer of rural surplus labor. Due to high mechanical level of modern agriculture, it is unnecessary to invest too many human resources in agricultural production; therefore, compared to labor shortage in cities, the rural labor is rich. It is able to take the group as unit to improve rural workers' quality to a higher level according to the features of different rural individuals and groups, thus improving their skills in different types of work, reducing the cost in transferring rural human resource, and also reducing the borne risk.

Secondly, it is required to expand the investment on rural education, and continuously improve the comprehensive quality of rural human resource. As the saying goes, "education is the foundation to plan our future”; according to Maslow's hierarchy of needs, after people's necessity of survival is satisfied, they will continuously seek for the need of higher level, that is, to obtain social esteem and self-actualization; the needs can be continuously satisfied via internal factor, and accepting education is the key means. In social practice, the need of esteem and self-actualization is generally endless and it will accompany people's whole life process. People's need changes with the change of external and internal environment. The need itself shows that there exists a kind of imbalance feature in organic entity, and it is a kind of reflection of desire on to which degree the external environment can satisfy people's need; the need also becomes the basic motivation for individuals to carry out some activities. There exists the relationship of mutual influence and promotion between different hierarchy of needs; no matter which hierarchy of need is regarded as the goal and motivation of action, it is able to 
promote the satisfaction of other hierarchy of need or form new round of goal and motivation while such hierarchy of need is satisfied. According to this need theory, in the rural human resource development, it is able to suit the remedy to the case according to specific demand, invest the limited materials and funds into the problems which should be urgently solved, and take this as an opportunity to promote the individuals of rural human resources to continuously perfect their quality via taking the needs as motivation. Through adding the investment on rural human resource development, it is able to improve comprehensive quality of labor force and use as an important means for increasing farmers' income; in particular, as the economic development has stronger and stronger dependence on science and technology today, whether a person has the ability to reserve and utilize scientific knowledge is closely related to income increase. Through improving development level, it is able to help rural labor force to master practical production and practice skills; in any field, the professional skill is always the entry point to exert the advantage of human resource, and also an important way of realizing the value. Therefore, it is required to continuously improvement the investment in rural education, make the best use of each financial resource, carry out comprehensive structure on rural education structure, improve development degree of rural human resource, expand the scale according to actual demand, perfect various kinds of vocational skill training, and provide useful talents to all industries of society; this is also the only road to optimize rural human resource. From perspective of national condition, China is still under the primary stage of socialism, and it is the biggest developing country in the world, thus it requires a long process to practically change cheap labor force into human resource. However, the most direct and effective way to improve the quality of rural labor is to enhance education, popularize the scientific cultural knowledge, let them get hold of advanced science and technology, and continuously obtain learning ability in production practice so that they can master useful knowledge and technology and lay a firm foundation for further improving their own value. The key points shall be investment on rural school-running, enhancing vocational training level, and gradually changing the physical strength-oriented human resource into skill-oriented human resource.

Thirdly, it is required to improve the social security level of rural human resource. As a whole, the social contribution and demand, investment of development cost and actual benefit of rural human resource can be considered based on the hierarchy of physiological needs, safety needs, love and belonging needs, esteem needs, and self-actualization needs. The first three hierarchies can be obtained from external environment, and the social security plays an important function in meeting people's basic needs. The prime thing is medical condition, which is related to health cost and long-term development benefit of rural human resource. From individual perspective, "health is the fundament of revolution"; in the practice of social production, the human resource is also a kind of consumption of resource; especially in the process of transfer of rural human resource to urban construction, most of industries they are engaged in are construction technology, exploitation of mineral resources, and social service, thus their health is threatened to certain degree, including damage of hazardous substance such as dust and chemical substances. Besides, some rural human resource engages in high-risk construction industry; if the security can't be guaranteed, they may lose their life or fall ill at any time. Therefore, it is required to not only create economic and convenient medical condition, continuously improve sanitary condition, enhance the subsidy on rural medical treatment and public health, and improve the overall quality of medical team, but also perfect systems and regulations related to personal insurance and industrial injury compensation. Furthermore, it is also required to consolidate and perfect new rural cooperation medical system, and let rural and urban human resource enjoy equal treatment; in this process, it is required to realize open and transparent medical expense, carry out regular review and rectification on conditions and quality of medical institutions, improve handling efficiency, and simplify and quicken medical service procedure so as to realize a harmonious and stable society. 


\section{Conclusion}

In conclusion, the main purpose of economic development in current world is to improve resource utilization level and reduce the influence on ambient environment; under the background of circular economy orientation, it is required to fully develop the value of rural human resource according to Chinese national condition, which not only conforms to the requirement of era and the rules of economic development, but also reflects human-oriented social development concept. Therefore, the investment to human resource development shall be implemented in place, and we shall always take enhancing the comprehensive quality of rural labor resource as core requirement, and integrate the concept of Maslow's hierarchy of needs into all links of human resource development to promote flexible adjustment of internal structure of human resource in management and application of human resource, continuously expand the space for wide rural human resource to exert their advantage, and promote social enterprises to keep moving towards sustainable direction. While the social and economic benefit is improved, a harmonious cultural atmosphere is created for continuous perfection of social economy.

\section{Acknowledgments}

Project name: Shaanxi provincial soft science project "Research on Rural Human Resource Development Problems of Shaanxi Province from Perspective of Urban-rural Coordinative Development” (Project No.: 2013KRM22-03).

\section{References}

[1] Wang Wenfeng. Research on Development of Rural Human Resource in Henan Province, Beijing Forestry University, 2013, 06 (24).

[2] Xiao Aili. Research on Rural Human Resource Development Problems in New Rural Construction in Jingzhou City, Yangtze University, 2013, 04 (01).

[3] Bai Yitong. Research on Rural Human Resource Development From Perspective of Human All-round Development, Guangxi Teachers Education University, 2013, 06 (01).

[4] Liu Wei. Research on Rural Human Resource Development Problems in New Rural Construction Process of Hubei Province, Yangtze University, 2013, 04 (01).

[5] Song Meili. Research on Rural Human Resource Development in East China, Ocean University of China, 2010, 09 (01).

[6] Xiao Chang. Research on Rural Human Resource Development under Information-based Background - take Huarong County of Hunan Province as an example, Central South University of Forestry and Technology, 2013, 12 (03).

[7] Yang Lan. Discussion on Application of Two-factor Theory in Salary Management, China Business \& Trade, 2010 (19).

[8] Ren Ju, Cai Guangjun. Discussion on Enterprise Management from Perspective of Maslow's Hierarchy of Needs, Modern Business Trade Industry, 2009 (2). 